\title{
TWO DIMENSIONAL TEMPERATURE DISTRIBUTION MODEL IN HUMAN DERMAL REGION EXPOSED AT LOW AMBIENT TEMPERATURES WITH AIR FLOW
}

\author{
D. B. Gurung \\ Department of Natural Sciences (Mathematics), School of Science, Kathmandu \\ University, Kathmandu, P.O. Box 6250, Kathmandu, Nepal \\ Corresponding address: db_gurung01@yahoo.com \\ Received 10 February 2012; Revised 30 October 2012
}

\begin{abstract}
This paper deals with thermo-regulation in human dermal part in a cold atmosphere with significant air flow. The mathematical model involving bio-heat equation has been solved using finite element method and Crank-Nicolson technique to numerically investigate two dimensional temperature distributions. The natural three layers of dermal part - epidermis, dermis, and subcutaneous tissue are considered for the study. The important parameters like blood mass flow rate, metabolic heat generation rate and thermal conductivity are taken distinct in each layer according to their distinct sub-regional activities. The human subject is assumed in static condition. The wind speed is considered in the range from the start of forced convection $(\approx 0.2 \mathrm{~m} / \mathrm{s})$ and up to $5 \mathrm{~m} / \mathrm{s}$. The loss of heat from the skin surface to the environment is taken due to convection, radiation, and insensible perspiration.
\end{abstract}

Keywords: finite element method; bio-heat equation; wind speed; dermal layers

AMS Subject Classification: 92C35, 65L60

\section{INTRODUCTION}

Human body maintains its body core temperature constant within small range between $(37-0.6)^{0} \mathrm{C}$ and $(37+0.6)^{0} \mathrm{C}$. The skin and subcutaneous tissue (SST) is the major organ that controls heat and moisture flow to and from the surrounding environment [1]. SST plays a key role for heat transfer within human body, and hence there is the variation of temperatures in the region in accordance with surrounding temperatures which is composed of three layers: epidermis, dermis, and subcutaneous tissue. The layer's geometry is irregular at the junction of the dermis where the epidermis projects into the dermis like cone called epidermal ridges (Fig. 1).

Heat distribution and temperature variation within tissue are related to the blood flow rates in arteries and veins, the blood flow perfusion through capillary tubes in tissue, the metabolic heat generation rate and heat conduction within tissue [2]. Thus the distribution of blood vessels in the layers of dermal part play an important attribute about the variation of biophysical and physiological quantities like the rate of blood mass flow, the rate of metabolic heat generation and the thermal conductivity in the layers of dermal region in accordance to its position. Epidermis contains dead cells; hence, there is no blood flow and no metabolic activity. The density of blood vessels increases gradually from the interface of epidermis and dermis towards subcutaneous tissue and become 
almost uniform in subcutaneous tissue. This gives us some idea about the variation of thermal conductivity, blood mass flow rate and metabolic heat generation rate in the layers of dermal region. The temperature variation within dermal region also depends on the geometry of the body and interaction between the human skin surface and surrounding. So, surrounding air flow is an important characteristic for temperature distribution within SST region. The loss of heat from the human body due to cold environment is quantified by convection air flow and radiative heat transfer on the skin surface. The faster the flow of air around the body, the thinner the boundary layer of air on the body's surface, and hence the lower the thermal insulation afforded the subject. The process of convection from heated sources such as human skin is classified as natural convection, and forced convection. The ambient air speed, $v<0.1 \mathrm{~m} / \mathrm{s}$ and $\geq 0.2 \mathrm{~m} / \mathrm{s}$ are considered respectively for natural convection and forced convection [3]. deDear et al.[3] recommended that the whole body natural convection coefficient for seated and standing thermal manikin are 3.3 and $3.4 \mathrm{~W} / \mathrm{m}^{2}-\mathrm{K}$ respectively.

Over the years many attempts have been made for empirical study of forced convection heat transfer concerning whole human body. The equation describing the dependence of whole body forced convection heat transfer coefficient, $h_{c}$ on air speed, $v$ is as follows

$$
h_{c}=B v^{n}\left(\mathrm{~W} / \mathrm{m}^{2}-\mathrm{K}\right)
$$

with most authors indicating $n$ in the range of 0.5 to 0.6 . deDear et al. [3] measured a value of $B=10.1, n=0.61$, and $B=10.4, n=0.58$ for whole body in static condition in seated and standing postures, respectively. However, regardless of posture, they recommended a general forced convection heat transfer coefficient of the body as

$$
h_{c}=10.3 \mathrm{v}^{0.6}\left(\mathrm{~W} / \mathrm{m}^{2}-\mathrm{K}\right)
$$

This is across a range of wind speed from the start of forced convection up to $5 \mathrm{~m} / \mathrm{s}$, and the value of $4.5 \mathrm{~W} / \mathrm{m}^{2}-\mathrm{K}$ for the radiative heat transfer coefficient, $h_{r}$ for the whole body.

When human body is exposed to cold environment it experiences different types of thermal stresses based on skin surface temperature. A hand skin surface temperature of $20^{\circ} \mathrm{C}$ is considered to be uncomfortably cold, $15^{\circ} \mathrm{C}$ to be extremely cold, and $5^{\circ} \mathrm{C}$ to be painfully cold [4]. 


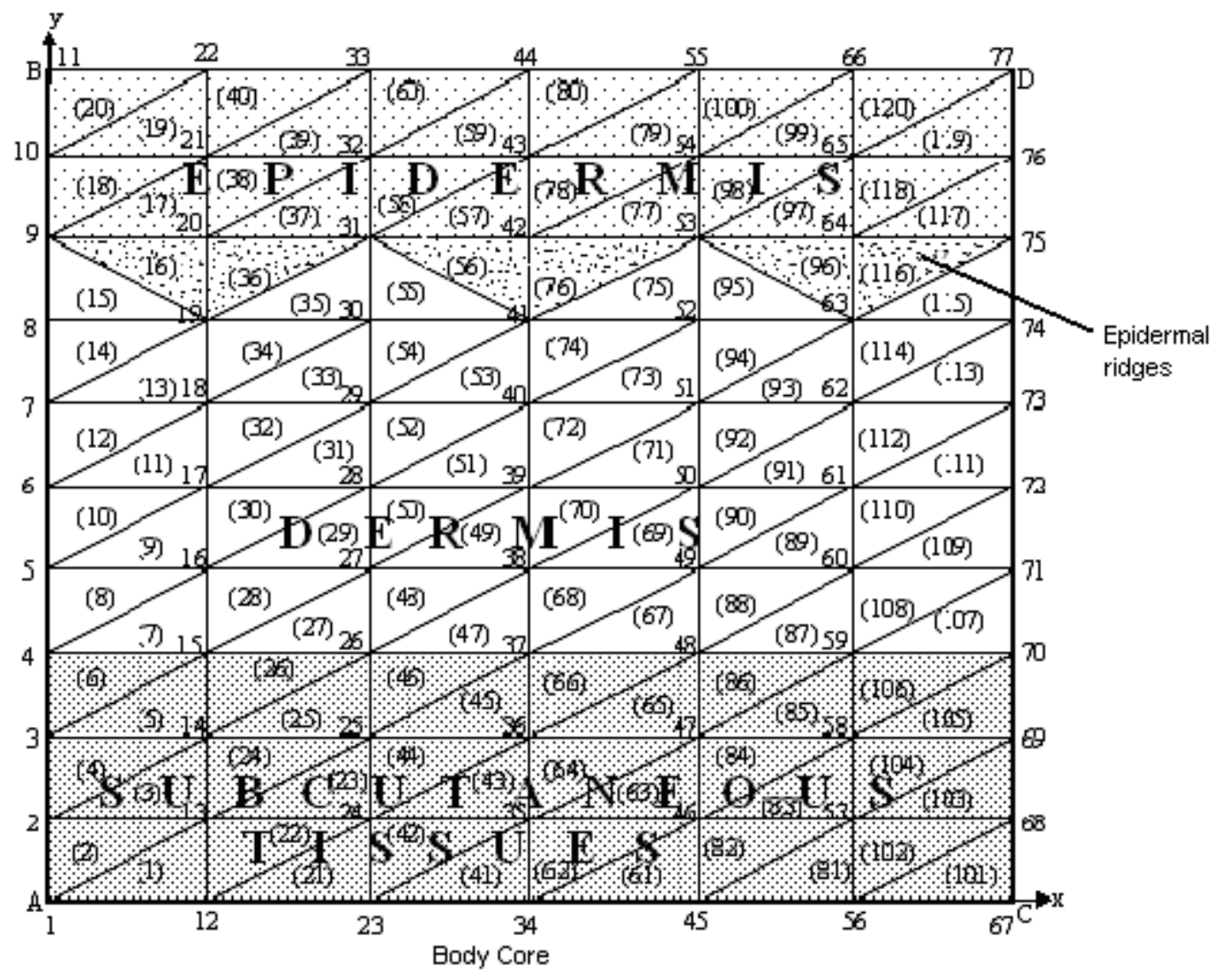

Fig. 1. Finite element discretization for dermal part. Numerals in brackets indicate the nodal elements and without brackets indicate the nodal numbers.

Many models have been developed for SST temperature distribution profile at normal and abnormal ambient temperatures for still air [5-9]. Earlier experimental investigations were made by Patterson [10] to obtain temperature profiles in the SST Region. The present study considers the effect of air flow with wind speed, $v$ in the range between 0.2 to $5 \mathrm{~m} / \mathrm{s}$ to predict the temperature variation in dermal layers irrespective of low surrounding temperatures.

\section{BIO-HEAT TRANSFER EQUATION}

Since the appearance of Pennes' bio-heat equation [11] variety of models on heat transfer in different tissue of human body have been proposed [12-17]. Pennes' equation suggest the consideration of blood perfusion to transfer heat from the blood to the tissue by Fick's principle and the heat rate on a volumetric basis is proportional to the volumetric blood perfusion rate and to the difference between the arterial and venous blood temperature. Pennes' bio-heat equation is one of the most useful approaches for predicting temperature variation in human body due to its computational simplicity and flexibility. It can be transformed into finite element method model. Following Pennes' suggestion, the thermal balance for perfused tissue considers the effect of blood perfusion and metabolism. These two effects were incorporated into the standard thermal diffusion equation given below: 


$$
\rho c \frac{\partial T}{\partial t}=\nabla \cdot K \nabla T+w_{b} c_{b} \rho_{b}\left(T_{a}-T\right)+q_{m e t}
$$

where $\rho, c$, and $K$ are the density, specific heat and thermal conductivity of skin tissue, respectively; $\rho_{b}$ and $c_{b}$ are the density and specific heat of blood; $w_{b}$ is the blood perfusion rate measured in volume of blood per volume of tissue per time; $T_{\mathrm{a}}$ and $T$ are the temperature of arterial blood and skin tissue, respectively; $q_{m e t}$ is the metabolic heat generation rate per unit volume.

Perl ${ }^{17}$ used Eq. (2.1) to illustrate heat distribution and tissue blood flow in body tissues by analyzing existing steady state and transient data obtained by Gibb's thermo electric probe method. Chao et al.[18,19] applied analytic method to solve steady and unsteady models to predict the temperature variation in regional dermal layers. Saxena [4] used Eq. (2.1) to find analytic solution for temperature distributions in the layers of dermal part by taking various values of parameters. Arya and Saxena [20] made attempt to study two dimensional steady state temperature distribution problems in skin and subcutaneous tissue for various values of environmental temperatures. Saxena et al. [9] used Eq. (2.1) to investigate the temperature distribution in human dermal part exposed to various values of environmental temperatures using quadratic shape function FEM approach. Gurung et al. [5] used Eq. (2.1) to study unsteady state temperature variation in dermal layers considering quadratic field variable. Agrawal et al. [21] constructed two dimensional thermal distributions model in dermal layers of elliptical shaped human limbs involving metastasis of tumors. Gurung and Saxena [6] used Eq. (2.1) to construct a model for one dimensional transient temperature distribution in human dermal part with protective layer at low atmospheric temperature.

\section{MATHEMATICAL MODEL AND METHODS}

We re-model the bio-heat Eq. (2.1) for two dimensional case by incorporating regional activities distinctly corresponding to the natural layers. Even inside the same layer, there exists large non-homogeneity and anisotropy due to the presence of blood vessels. Blood mass flow rate and metabolic heat generation rate rely on density of blood vessels at different depths. Therefore, it is reasonable to consider $M=w_{b} \rho_{b} c_{b}$ and $q_{\text {met }}$ negligible in epidermis, constant throughout in subcutaneous tissue and less than the values of subcutaneous tissue in dermis.

In the model, the skin has been considered as a vertical cross-section of two dimensional rectangular SST regions with body core along $\mathrm{x}$-axis and the thickness along $\mathrm{y}$-axis (Figure 1). The whole SST region is discretized into 120 nodal elements with triangular shape having in total 77 nodes with 36 nodal elements for subcutaneous tissue, 54 nodal elements for dermis, 6 nodal elements for epidermal part projected into the dermis, and 24 nodal elements for epidermal part not penetrating the dermis.

Due to the minute thickness of the regions and for the simplicity of calculation, the linear shape functions are considered to approximate the temperature profiles. Thus, for general nodal element, $e$, we take 


$$
T^{(e)}=C_{1}^{(e)}+C_{2}^{(e)} x+C_{3}^{(e)} y
$$

where $C_{1}^{(e)}, C_{2}^{(e)}$, and $C_{3}^{(e)}$ are time dependent coefficients, and they can be determined in terms of nodal temperatures $T_{i}^{(e)}, T_{j}^{(e)}$, and $T_{k}^{(e)}$ at the corners $i, j$ and $k$ of element $(e)$ (Fig. 2).

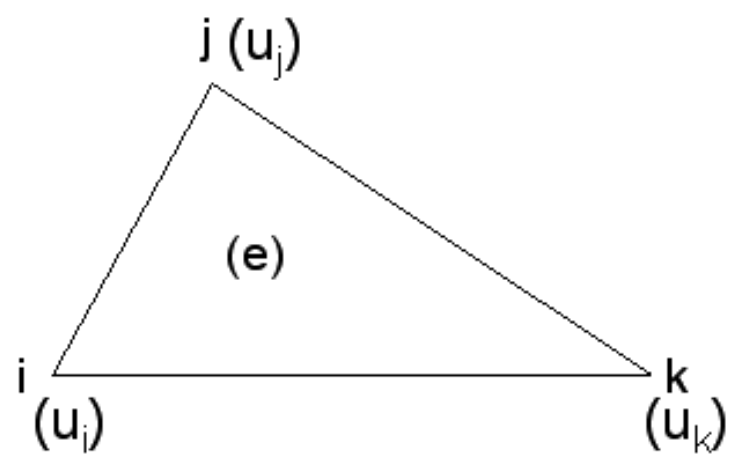

Fig. 2. Triangular element

At micro-level, arterial blood temperature, $T_{a}$ is dominated by body core temperature, $T_{b}$. So, the bio-heat Eq. (2.1) in two dimensional unsteady state case takes the form

$$
\rho c \frac{\partial T}{\partial t}=\frac{\partial}{\partial x}\left(K \frac{\partial T}{\partial x}\right)+\frac{\partial}{\partial y}\left(K \frac{\partial T}{\partial y}\right)+M\left(T_{b}-T\right)+q_{m e t}
$$

where $\mathrm{x}$ and $y$ are cartesian coordinates.

In the two dimensional discretization of the skin and subcutaneous tissue the thickness ' $a$ ' of SST region has been taken along y-axis, and the loss of heat from the outer skin surface has been considered due to convection, radiation, and insensible perspiration. Thus the heat flux from outer skin surface is given by

$$
-\left.K \frac{\partial T}{\partial y}\right|_{y=a}=h_{c o m}\left(T-T_{a t m}\right)+L E
$$

where $h_{\text {com }}=h_{c}+h_{r}, \mathrm{~T}_{\mathrm{atm}}, \mathrm{L}$, and $\mathrm{E}$ are, respectively, combined heat transfer coefficients due to convection and radiation, atmospheric temperature, latent heat of evaporation, and rate of sweat evaporation. The transport of heat within tissue occurs along normal to the skin surface from body core, and hence we can assume negligible heat flux in x-direction. So the other boundary conditions are assumed to be

$$
\begin{aligned}
& \left.\frac{\partial T}{\partial x}\right|_{x=0}=0 \\
& \left.\frac{\partial T}{\partial x}\right|_{x=w}=0
\end{aligned}
$$


with the initial condition

$$
T(x, 0)=T_{b}=37^{0} C
$$

where $\mathrm{w}$ is the total width of the skin taken along $\mathrm{x}$ - direction. The boundary conditions (Eq. (3.4) and Eq. (3.5)) correspond to the situation when there is no outward normal flow from the boundaries $\mathrm{AB}$ and $\mathrm{CD}$.

\section{SOLUTION}

The dermal layers are inhomogeneous and irregular. Therefore, we can use finite element method technique based on variational principle.

The variational integral

$$
I=\int_{x_{1}}^{x_{2}} F\left(x, y, T, T_{x}, T_{y}\right) d x
$$

in optimum form is equivalent to Euler-Lagrange differential equation[Myers].

$$
\frac{\partial F}{\partial T}-\frac{\partial}{\partial x}\left(\frac{\partial F}{\partial T_{x}}\right)-\frac{\partial}{\partial y}\left(\frac{\partial F}{\partial T_{y}}\right)=0
$$

where $T_{x}=\frac{\partial T}{\partial x}$ and $T_{y}=\frac{\partial T}{\partial y}$.

If the finite element equations are derived on the basis of a variational principle, the boundary conditions (Eqs. (3.4), (3.5) and (3.6)) will be automatically incorporated in the formulation; hence only the boundary condition (3.3) is to be enforced on the solution [22]. The partial differential Eq. (3.2) coupled with boundary condition (3.3) in two dimensional unsteady state case and compared with Euler-Lagrange differential Eq. (4.2) is transformed into the following variational form [23]:

$$
\begin{aligned}
I= & \frac{1}{2} \iint_{A}\left[K\left\{\left(\frac{\partial T}{\partial x}\right)^{2}+\left(\frac{\partial T}{\partial y}\right)^{2}\right\}+M\left(T_{b}-T\right)^{2}-2 q_{m e t} T\right] d A \\
& +\frac{1}{2} \iint_{A}(\rho c) \frac{\partial T^{2}}{\partial t} d A+\frac{1}{2} \int_{B}\left[h_{c o m}\left(T-T_{a t m}\right)^{2}+2 L E T\right] d x
\end{aligned}
$$

where $A$ is the area of the region of dermal part considered and $B$ is the total width of outer skin boundary.

In the model, the finite element discretization consists 120 elements, So

$$
I=\sum_{e=1}^{120} I^{(e)}
$$

where 


$$
\begin{aligned}
I^{(e)} & =\frac{1}{2} \iint_{A^{(e)}}\left[K^{(e)}\left\{\left(\frac{\partial T^{(e)}}{\partial x}\right)^{2}+\left(\frac{\partial T^{(e)}}{\partial y}\right)^{2}\right\}+M^{(e)}\left(T_{b}-T^{(e)}\right)^{2}-2 q_{m e t}^{(e)} T^{(e)}\right] d A^{(e)} \\
& +\frac{1}{2} \iint_{A^{(e)}}(\rho c)^{(e)} \frac{\partial\left(T^{(e)}\right)^{2}}{\partial t} d A^{(e)}+\frac{1}{2} \int_{B^{(e)}}\left[h_{c o m}\left(T^{(e)}-T_{a t m}\right)^{2}+2 L E T^{(e)}\right] d x
\end{aligned}
$$

Here $\mathrm{A}^{(\mathrm{e})}$ is the area of the nodal element $(\mathrm{e})$, and $\mathrm{B}^{(\mathrm{e})}$ is the width of the element lying at the outer skin boundary. In the finite element discretization, the nodal elements with numbers 20, 40, 60, 80, 100, and 120 are at the outer skin boundary of the SST region. $\mathrm{B}^{(\mathrm{e})}$ is employed for these elements only.

The integral Eq. (4.5) is broken into five parts as

$$
I^{(e)}=I_{K}^{(e)}+I_{M}^{(e)}-I_{q}^{(e)}+I_{t}^{(e)}+I_{h}^{(e)}
$$

where

$$
\begin{aligned}
& I_{K}^{(e)}=\frac{1}{2} \iint_{A^{(e)}}\left[K^{(e)}\left\{\left(\frac{\partial T^{(e)}}{\partial x}\right)^{2}+\left(\frac{\partial T^{(e)}}{\partial y}\right)^{2}\right\}\right] d A^{(e)} \\
& I_{M}^{(e)}=\frac{1}{2} \iint_{A^{(e)}}\left[M^{(e)}\left(T_{b}-T^{(e)}\right)^{2}\right] d A^{(e)} \\
& I_{q}^{(e)}=\iint_{A^{(e)}} q_{m e t}^{(e)} T^{(e)} d A^{(e)} \\
& I_{t}^{(e)}=\frac{1}{2} \iint_{A^{(e)}}(\rho c)^{(e)} \frac{\partial\left(T^{(e)}\right)^{2}}{\partial t} d A^{(e)} \\
& I_{h}^{(e)}=\frac{1}{2} \int_{B^{(e)}}\left[h_{c o m}\left(T^{(e)}-T_{a t m}\right)^{2}+2 L E T^{(e)}\right] d x
\end{aligned}
$$

For the whole region the variational integral $I$ is

$$
I=\sum_{e=1}^{120} I^{(e)}=\sum_{e=1}^{120} I_{K}^{(e)}+\sum_{e=1}^{120} I_{M}^{(e)}-\sum_{e=1}^{120} I_{q}^{(e)}+\sum_{e=1}^{120} I_{t}^{(e)}+\sum_{e=1}^{120} I_{h}^{(e)}
$$

Now to optimize $I$, let us differentiate it with respect to each nodal temperature $T_{i}$ except at the core boundary and then set the derivatives equal to zero, i.e.,

$$
\frac{\partial I}{\partial T_{i}}=0
$$

Eq. (4.8) leads to a linear system of differential equations of the type

$$
C \frac{d T}{d t}+P T=B
$$


where $T$, the transpose of the row matrix $\left[\begin{array}{llllllll}T_{1} & T_{2} & \cdots & T_{i} & T_{j} & T_{k} & \cdots & T_{77}\end{array}\right]$, is to be determined. $\mathrm{P}$ and $\mathrm{C}$ are square matices of order $77 \times 77$ and $\mathrm{B}$ is a column matrix of order $77 \times 1$. The values of the elements of these matrices depend on the values of biophysical and physiological parameters.

The system of ordinary differential Eqs. (4.9) has been solved using the Crank-Nicolson method. This method gives the solution of the system with regard to time according to the relation

$$
\left(C+\frac{\Delta t}{2} P\right) T^{(i+1)}=\left(C-\frac{\Delta t}{2} P\right) T^{(i)}+\Delta t B
$$

where $\Delta t$ is small time interval;

$$
T^{(0)}=\left[\begin{array}{c}
T_{1} \\
T_{2} \\
\vdots \\
T_{i} \\
T_{j} \\
T_{k} \\
\vdots \\
T_{77}
\end{array}\right]^{(0)} ; \quad T^{(i)}=\left[\begin{array}{c}
T_{1} \\
T_{2} \\
\vdots \\
T_{i} \\
T_{j} \\
T_{k} \\
\vdots \\
T_{77}
\end{array}\right]^{(i)} ; \text { and } \quad T^{(i+1)}=\left[\begin{array}{c}
T_{1} \\
T_{2} \\
\vdots \\
T_{i} \\
T_{j} \\
T_{k} \\
\vdots \\
T_{77}
\end{array}\right]^{(i+1)}
$$

The skin temperature of $32^{\circ} \mathrm{C}$ pertains to a thermo neutral condition when the human body is exposed to cold environment [24]. Accordingly, we consider

$$
T^{(0)}=\left[\begin{array}{lllll}
32 & \cdots & 32 & \cdots & 32
\end{array}\right]_{1 \times 77}^{T}
$$

\section{NUMERICAL RESULTS AND DISCUSSION}

The nude human subject is assumed to be exposed to cold environment with various ambient temperatures. This result constriction of blood vessels causing decrease in blood mass flow rate in blood vessels which in turn decreases the heat carried by blood to the skin surface. This causes increase in metabolic heat generation rate to keep core temperature constant. To solve Eqs. (4.10), we take the following values of parameters in the layer-wise elements of the dermal region of the discretized fig. 1 as given in Table 1. 
Table 1. Numerical values of parameters $[3,5,8,18,19]$

\begin{tabular}{|c|c|}
\hline \multicolumn{2}{|l|}{ Thickness of layers (m) } \\
\hline Epidermis & 0.0010 \\
\hline Dermis & 0.0025 \\
\hline Subcutaneous tissue & 0.0015 \\
\hline \multicolumn{2}{|l|}{ Thermal conductivity $\left(\mathrm{W} / \mathrm{m}^{0} \mathrm{C}\right)$} \\
\hline Epidermis & 0.209 \\
\hline Epidermal ridges & 0.209 \\
\hline Dermis & 0.314 \\
\hline Subcutaneous tissue & 0.418 \\
\hline \multicolumn{2}{|c|}{ Product of blood mass flow rate and specific heat of blood $\left(\mathrm{W} / \mathrm{m}^{3}{ }^{0} \mathrm{C}\right)$} \\
\hline Epidermis & 0 \\
\hline Epidermal ridges & $m / 2$ \\
\hline Dermis & $2 m / 3$ \\
\hline Subcutaneous tissue & $m=2.093 \times 10^{2}$ \\
\hline \multicolumn{2}{|c|}{ Metabolic heat generation rate $\left(\mathrm{W} / \mathrm{m}^{3}\right)$} \\
\hline Epidermis & 0 \\
\hline Epidermal ridges & $q / 12$ \\
\hline Dermis & $q / 6$ \\
\hline Subcutaneous tissue & $q=3.767 \times 10^{3}$ \\
\hline \multicolumn{2}{|l|}{ Latent heat $(\mathrm{J} / \mathrm{kg})$} \\
\hline $\mathrm{L}$ & $2.424 \times 10^{6}$ \\
\hline \multicolumn{2}{|l|}{ Evaporation rate $\left(\mathrm{kg} / \mathrm{m}^{2}-\mathrm{s}\right)$} \\
\hline$E$ & 0 \\
\hline \multicolumn{2}{|c|}{ Radiative heat transfer coefficient $\left(\mathrm{W} / \mathrm{m}^{2}{ }_{-}{ }^{0} \mathrm{~K}\right)$} \\
\hline \multicolumn{2}{|c|}{ Convective heat transfer coefficient $\left(\mathrm{W} / \mathrm{m}^{2}{ }^{0}{ }^{0} \mathrm{~K}\right)$} \\
\hline \multicolumn{2}{|l|}{ Tissue density $\left(\mathrm{kg} / \mathrm{m}^{3}\right)$} \\
\hline$\rho$ & $1.05 \times 10^{3}$ \\
\hline \multicolumn{2}{|l|}{ Tissue specific heat $\left(\mathrm{J} / \mathrm{kg}^{0} \mathrm{C}\right)$} \\
\hline$c$ & $3.474 \times 10^{3}$ \\
\hline \multicolumn{2}{|l|}{ Tissue width considered (m) } \\
\hline$w$ & 0.001 \\
\hline
\end{tabular}

It is assumed that the skin surface has been exposed to $20 \mathrm{mins}$ at atmospheric temperatures of 2 and $-5^{\circ} \mathrm{C}$ at different wind speed not exceeding $5 \mathrm{~m} / \mathrm{s}$. Accordingly, we obtain the values of nodal temperatures at different time interval within 20 mins. The temperature distributions for nodal temperature on nodes lying along $2^{\text {nd }}$ column and $2^{\text {nd }}$, $6^{\text {th }}$ and $10^{\text {th }}$ rows of two-dimensional discretized figure (Fig. 1) have been plotted (Figs. 3 $-7)$. 
(i) The Figures show that the steady state temperature of the SST region changes markedly towards the outer skin surface from the body core with the change in environmental temperature at an equal wind speed. This is because of heat loss through the skin surface, and the fat deposited in subcutaneous layer acting as heat insulator to the body.

(ii) Effect of wind flow on the temperature distribution at an equal environmental temperature for various wind speed are noticed from the nodal temperatures shown in Figs. 3 - 7. In these figures, it can be seen that the variation of tissue temperature occurs more towards skin surface from the body core. This is due to increase in heat loss from the outer skin surface to the environment for the increase of wind speed.

(iii) From the figures it is observed that the body experiences extremely cold below the environmental temperature of $2^{0} \mathrm{C}$ at wind speed $2 \mathrm{~m} / \mathrm{s}$. But body starts to experience painfully cold at an environmental temperature of $-5^{0} \mathrm{C}$ and wind speed $2 \mathrm{~m} / \mathrm{s}$.

\section{CONCLUSION}

A model based on Pennes equation has been constructed to simulate the physiological responses to heat and cold in nude human subject at various wind speed. The physiological thermo-regulation involves changes in blood mass flow rate, metabolic heat generation rate and thermal conductivity of tissue in accordance with the layers of dermal part. It can be used to predict the cold environment temperature and wind speed that causes thermal stresses to human body by establishing the temperature profiles for skin surface. The model has used the explicit convection heat transfer relation of de Dear et al. [ 3] obtained by regressing the experimental data. So the present model limits the wind speed from $0.2 \mathrm{~m} / \mathrm{s}$ to $5 \mathrm{~m} / \mathrm{s}$. The work can further be extended for unlimited wind speed.

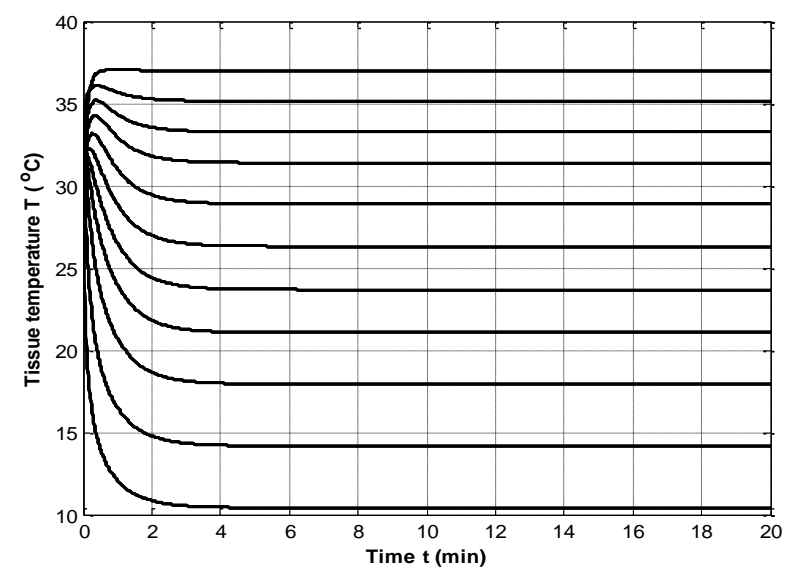

Fig. 3. Temperature distributions for $2^{\text {nd }}$ column nodes in SST region for $T_{\text {atm }}=2^{0} \mathrm{C}$ and wind speed $2 \mathrm{~m} / \mathrm{s}$. The graphs from above to below represent the graphs of nodes lying in $2^{\text {nd }}$ column counted from body core node towards skin surface node. 


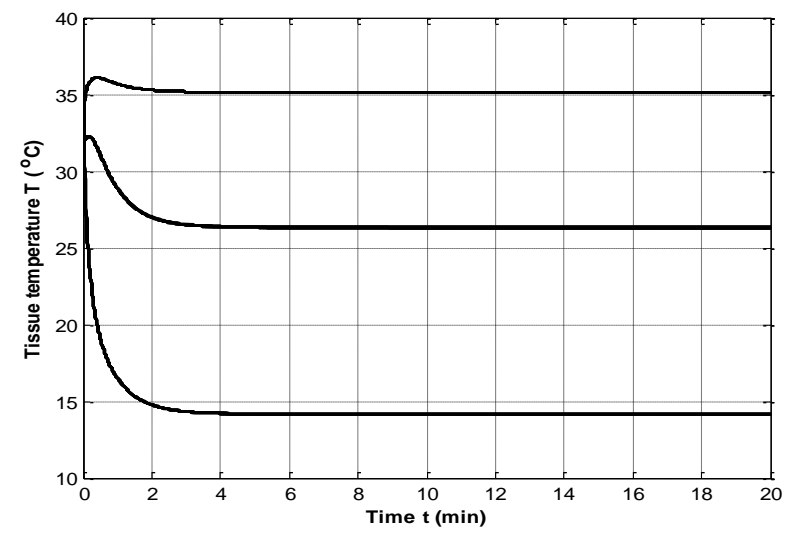

Fig. 4. Temperature distributions for $2^{\text {nd }}, 6^{\text {th }}$ and $10^{\text {th }}$ row nodes in SST region for $T_{\text {atm }}=$ $2^{0} \mathrm{C}$ and wind speed $2 \mathrm{~m} / \mathrm{s}$. The graphs from below to above represent the graphs of nodes lying in $2^{\text {nd }}, 6^{\text {th }}$ and $10^{\text {th }}$ columns respectively.

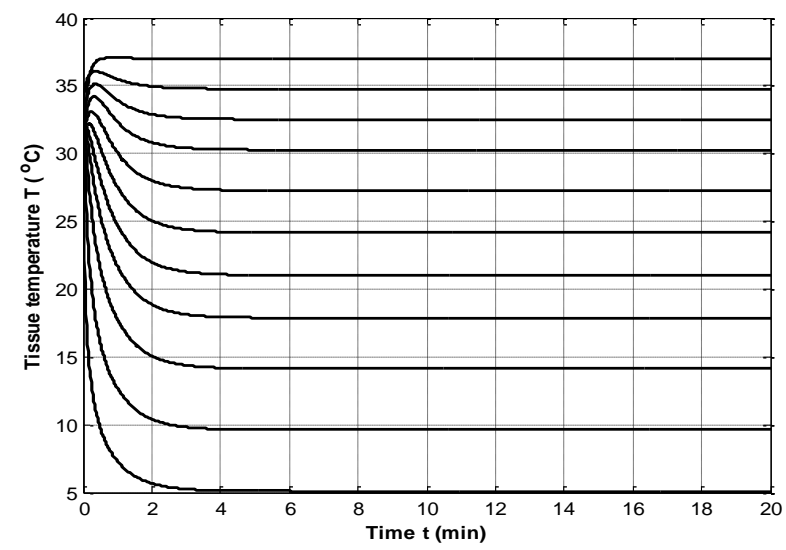

Fig. 5. Temperature distributions for $2^{\text {nd }}$ column nodes in SST region for $T_{\text {atm }}=-5^{0} \mathrm{C}$ and wind speed $2 \mathrm{~m} / \mathrm{s}$. The graphs from above to below represent the graphs of nodes lying in $2^{\text {nd }}$ column counted from body core node towards skin surface node. 


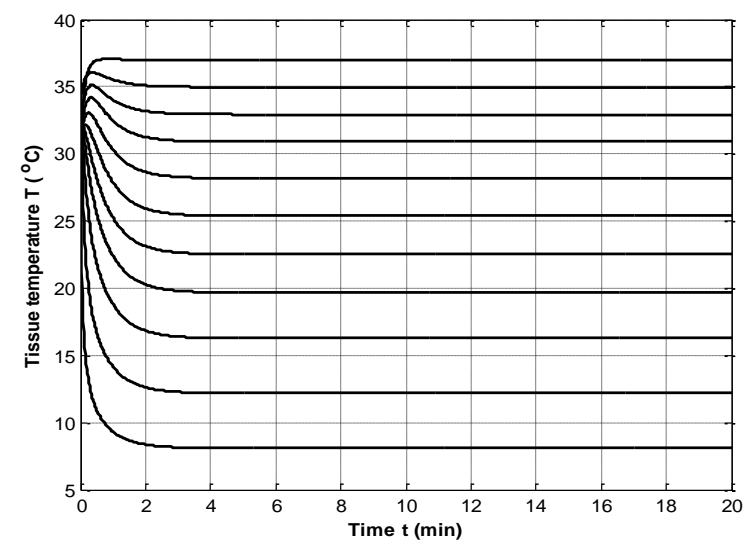

Fig. 6. Temperature distributions for $2^{\text {nd }}$ column nodes in SST region for $T_{\text {atm }}=2^{0} \mathrm{C}$ and wind speed $4 \mathrm{~m} / \mathrm{s}$. The graph from above to below represent the graphs of nodes lying in $2^{\text {nd }}$ column counted from body core node towards skin surface node.

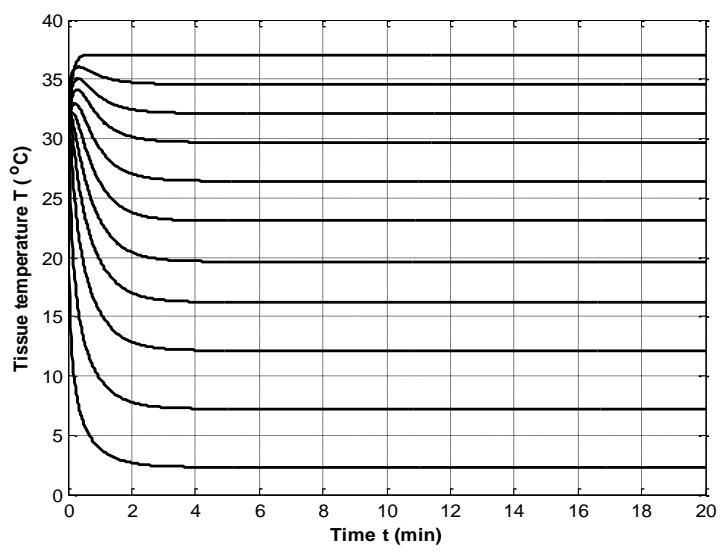

Fig. 7. Temperature distributions for $2^{\text {nd }}$ column nodes in SST region for $T_{\text {atm }}=-5^{0} \mathrm{C}$ and wind speed $4 \mathrm{~m} / \mathrm{s}$. The graphs from above to below represent the graphs of nodes lying in $2^{\text {nd }}$ column counted from body core node towards skin surface node.

\section{ACKNOWLEDGMENTS}

The author would like to thank Prof. V P Saxena, Director Sagar Institute of Research and Technology, Bhopal, India for his valuable suggestion in the work. The author is also thankful to referees for their valuable comments and suggestions to present the work in this form.

\section{REFERENCES}

[1] Guyton A C \& Hall J E, Text book of medical physiology, Elsevier, 2008. 
[2] Xuan Y \& Roetzel W, Bioheat equation of the human thermal system, Chem. Eng. Technol., 20 (1997) 268.

[3] Dear J de, Edward A, Zhang H \& Masayuki O, Convective and radiative heat transfer coefficients for individual human body segments, Int. J. Biometerol., 40 (1997) 141.

[4] Cengel Y A, Heat transfer, A practical approach, Tata McGraw Hill Edition, (2004) 40.

[5] D. B. Gurung D B, Saxena V P \& Adhikary P R, FEM approach to one dimensional unsteady state temperature distribution in human dermal parts with quadratic shape functions, J Appl. Math \& Informatics, 27 (2009) 301.

[6] Gurung D B \& Saxena V P, Transient temperature distribution in human dermal part with protective layer at low atmospheric temperature, International Journal of Biomathematics, 3(4) (2010) 439.

[7] Khanday M A \& Saxena V P, Finite element estimation of one-dimensional unsteady state heat regulation in human head exposed to cold environment, Journal of Biological systems, 17 (4) (2009) 853.

[8] Saxena V P, Temperature distribution in human skin and subcutaneous tissue, $J$. Theor. Biol., 102 (1983) 277.

[9] Saxena V P, Gurung D B \& Adhikary P R, Quadratic shape function FEM approach to temperature distribution problem in peripheral layers of human body, Bulletin of Allahabad Mathematical society, 22 (2007) 21.

[10] Patterson A M, Transient response of intra dermal temperature profile in man to changes in air temperature, South Afr. J. Sc., 74 (1978) 136.

[11] Pennes $\mathrm{H} \mathrm{H}$, Analysis of tissue and arterial blood temperature in the resting human forearm, J. Appl. Physiol., 1 (1948) 93.

[12] Chen M M \& Holmes K R, Microvascular contributions in tissue heat transfer, Ann N Y Acad Sci. 335 (1980) 137.

[13] Killer K H \& Seiler L, An analysis of peripheral heat transfer in man, J. Appl. Physiol., 30 (1971) 779.

[14] Mitchell J W \& Myers G E, An analytic model of the countercurrent heat exchange phenomena, J. Bio. Phys., 8 (1968) 897.

[15] Perl W, Heat and matter distribution in body tissues and the determination of tissue blood flow by local clearance method, J. Theor. Biol., 2 (1962) 201. 
[16] Weinbaum S \& Jiji L M, A new simplified bioheat equation for the effect of blood flow on local average tissue temperature, ASME Trans J. Biomech. Eng., 107 (1985) 131.

[17] Wuff W, The energy conservation equation for living tissue, IEEE Trans. Biomed. Eng., 21 (1974) 494.

[18] Chao K N, Eisley J G \& Yang W J, Heat and water migration through normal skin: Part I - Steady state, Med. Bio. Eng. And Comput., 17 (1979) 301.

[19] Chao K N, Eisley J G \& Yang W J, Heat and water migration through normal skin: Part II - Unsteady state, Med. Bio. Eng. And Comput. 17 (1979) 311.

[20] Arya D \& Saxena V P, Temperature variation in skin and subcutaneous layers under different environmental condition - A two dimensional study, Indian $J$ Pure Appl. Math. 17(1) (1986) 84.

[21] Agrawal M, Adlakha N \& Pardasani K R, Thermal disturbances in dermal regions of of human limbs involving metastasis of tumors, International Mathematics Forum, 5 (2010) 1903.

[22] Rao S S, The Finite Element Method in Engineering, Elsevier, (2009) 169.

[23] Myers G E, Analytic methods in conduction heat transfer, Mc. Graw Hill, New York, (1971) 320.

[24] Gavhed D, Makinen T, Holmer I \& Rintamaki H, Face temperature and cardiorespiratory responses to wind in thermoneutral and cool exposed to $-10^{\circ} \mathrm{C}$, Eur. J. Appl. Physiol. 83 (2000) 449. 